\title{
O Curso de Desenho de Propaganda e de Artes Gráficas da FGV e o Ensino da Gravura como Arte Aplicada - Rio de Janeiro, 1946
}

The Advertisement Design and Graphic Arts Course at FGV and the Teaching of Engraving as an Applied Art

FONTANA, Carla Fernanda; Doutoranda; Universidade de São Paulo

carlaff@usp.br

\begin{abstract}
Resumo
Este artigo apresenta e descreve o Curso de Desenho de Propaganda e Artes Gráficas promovido pela Fundação Getúlio Vargas do Rio de Janeiro em 1946, resgatando essa iniciativa pioneira. O curso visava contribuir para a melhoria da qualidade dos impressos brasileiros, formando artistas gráficos que atuariam desenhando e projetando impressos, como livros, jornais e revistas, além de ilustrações, anúncios e cartazes publicitários, atendendo, assim, as demandas de uma área carente de profissionalização. Com orientação de Tomás Santa Rosa Jr., reconhecido artista gráfico do período, o curso contou com outros nomes importantes entre seus professores, como os gravadores Axel de Leskoschek e Carlos Oswald. Apesar de sua curta duração, a experiência serviu como iniciação dos estudantes no campo das artes, gráficas ou plásticas, com diversos deles se especializando, posteriormente, em diferentes áreas de atuação e contribuindo efetivamente para o desenvolvimento das artes gráficas no Brasil.
\end{abstract}

Palavras Chave: artes gráficas; gravura; Tomás Santa Rosa.

\begin{abstract}
This paper presents and describes the Advertisement Design and Graphic Arts course promoted by the Getúlio Vargas Foundation of Rio de Janeiro in 1946, shedding light on this pioneering initiative. The course sought to improve the quality of Brazilian printed matter, educating graphic artists who would work designing printed materials, such as books, magazines, and newspapers, as well as illustrations, advertisements and posters, thus meeting the demands of an area lacking professionalization. With the guidance of Tomás Santa Rosa Jr., a recognized graphic artist of the period, the course had other important professors, such as the engravers Axel de Leskoschek and Carlos Oswald. In spite of its short duration, the course initiated its students in the arts, graphic or plastic, and several of them would later specialize in different fields, contributing effectively to the development of graphic arts in Brazil.
\end{abstract}

Keywords: graphic arts; engraving; Tomás Santa Rosa. 


\section{O Curso: Contexto e Objetivos}

Em 1946, a Divisão de Ensino da Fundação Getúlio Vargas (FGV) do Rio de Janeiro promoveu um Curso de Desenho de Propaganda e de Artes Gráficas, sob a orientação de Tomás Santa Rosa Jr. O objetivo do curso era o de capacitar os alunos para exercerem atividades profissionais relacionadas à publicidade e às artes gráficas, o que se fazia necessário, de acordo com a FGV, em virtude da expansão que os livros, as revistas e os jornais vivenciavam naquele momento no Brasil ${ }^{1}$.

Nas palavras do próprio Santa Rosa, o curso visava "capacitar os seus alunos à solução dos problemas gráficos, criando-lhes uma mentalidade ágil, à altura das solicitações do trabalho" ${ }^{2}$. 0 curso habilitaria os profissionais nele formados a atuarem na imprensa, em edições e nos meios publicitários, onde havia, como seu orientador declarou, "grande pobreza de material humano capaz", de modo que "os jornais se beneficiarão com paginadores de nova visão, as editoras com ilustradores possuidores de todas as técnicas, e as agências de publicidade com 'lay-outmans' e cartazistas" ${ }^{3}$.

Já no relatório de atividades do ano de 1945, a Fundação anunciara o plano de realizar, no ano seguinte, cinco "cursos de desenho", entre eles o de "desenho de cartazes e artes gráficas" Todos os cursos de desenho teriam caráter prático, baseados no princípio de se aprender fazendo, e o de artes gráficas deveria promover "a formação [do] profissional que, com as noções de arte e de psicologia e técnica de propaganda, queira se especializar na execução de cartazes e outras composições gráficas de publicidade, podendo candidatar-se ao serviço nas empresas de artes gráficas; propaganda; imprensa, etc." ${ }^{5}$. Os outros cursos de desenho planejados para o ano de 1946 eram de desenho básico, de desenho cartográfico e topográfico, de desenho de órgãos de máquinas e ferramentas e de desenho aplicado às ciências naturais, mas o único efetivamente ministrado foi o de artes gráficas ${ }^{6}$.

A realização do curso contou com o empenho de seu orientador, e teria sido uma "velha aspiração" do próprio Santa Rosa "levantar o gosto pelas artes gráficas em nosso meio", de acordo com seu depoimento:

\footnotetext{
Quando dirigia o curso de pintura da Universidade do Distrito Federal, Candido Portinari me havia escolhido para realizar igual iniciativa lá, porém, a Universidade foi fechada e a ideia ficou no ar. Mais tarde propus ao ministro Capanema a criação de um atelier livre com o mesmo fim, coisa que também encontrou muitas dificuldades.

Agora, porém, enfim, posso ver realizada uma ideia que se impunha, em face das necessidades do nosso meio gráfico e artístico ${ }^{7}$.

${ }^{1}$ Fundação Getúlio Vargas, Divisão de Ensino, Curso de Desenho de Propaganda e de Artes Gráficas [folheto de divulgação do curso], 1946, p. 3.

2 “Fala o Pintor Santa Rosa sobre o Curso de Artes Gráficas”, Rio de Janeiro, A Manhã, p. 3, 24 mar. 1946.

3 Idem.

${ }^{4}$ Fundação Getúlio Vargas, Relatório Anual de Prestação de Contas [Relativo a 1945], 1946, p. 43.

${ }^{5}$ Idem, p. 45.

${ }^{6}$ Fundação Getúlio Vargas, Relatório e Balanço do Exercício de 1946, 1947.

7 "Fala o Pintor Santa Rosa sobre o Curso de Artes Gráficas", op. cit.
} 


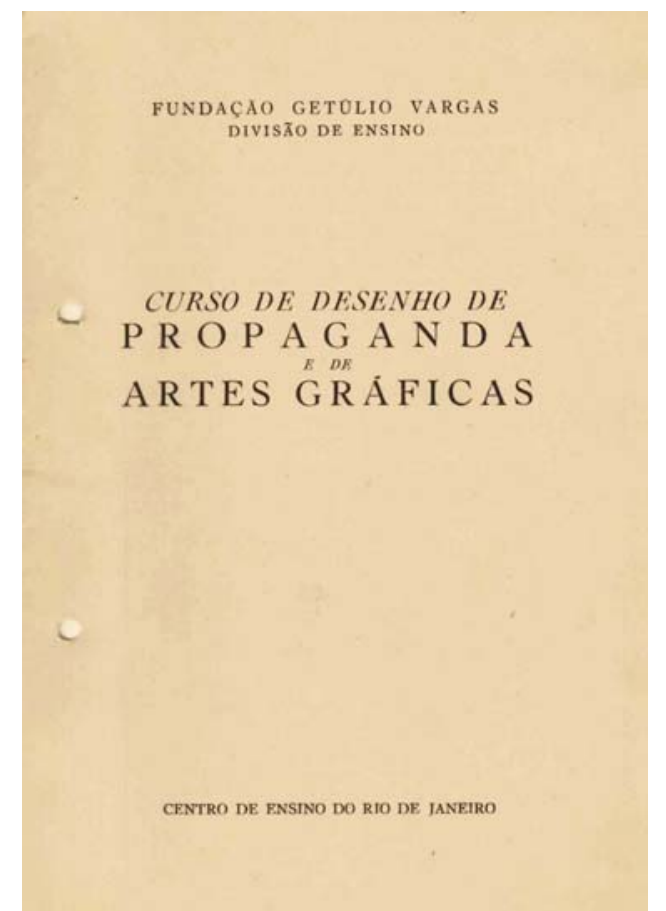

FIgURA 1. Capa do folheto de divulgação do Curso de Desenho de Propaganda e de Artes Gráficas promovido pela FGV em 1946.

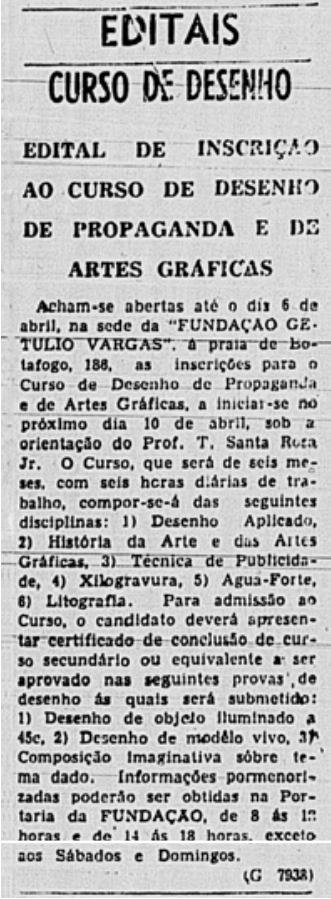

FIGURA 2. Edital de inscrição no curso da FGV publicado no Correio da Manhã em 3 de abril de 1946.

A iniciativa do curso foi destacada como pioneira pela imprensa da época, que também elogiou as possibilidades de aplicação prática de seus ensinamentos e os benefícios que traria para as publicações nacionais, elevando sua qualidade.

Do que se sabe, a experiência desse curso de desenho, nos moldes em que foi promovido pela FGV em 1946, é de fato pioneira. Não se conhecem registros de cursos com características semelhantes em época anterior, sendo que os profissionais atuantes no campo que o curso pretendia abranger formavam-se, em geral, no dia a dia do trabalho, como aprendizes nas próprias empresas gráficas, editoriais ou jornalísticas. Os cursos de belas-artes, embora ensinassem desenho, não contemplavam a parte técnica relacionada ao processo industrial de produção de impressos, e visavam a formação de artistas plásticos, tais como pintores e escultores, e não a de profissionais das artes gráficas. Também o Liceu de Artes e Ofícios do Rio de Janeiro que, há anos, oferecia cursos para preparar mão de obra destinada à tipografia e, desde 1930, um de gravura, não tinha por objetivo formar desenhistas para atender as necessidades editoriais. Já os cursos destinados à formação de gráficos, tais como o da Escola de Aprendizagem de Artes Gráficas da Imprensa Nacional, do Rio de Janeiro, criada em 1942, e o do Senai - Serviço Nacional de Aprendizagem Industrial, instituído em 1945 em São Paulo, restringiam-se à formação de mão de obra para diferentes setores das oficinas gráficas, tais como composição tipográfica, impressão e encadernação ${ }^{8}$.

O curso da FGV visava, portanto, a atender as demandas de uma área carente de profissionalização, de modo a contribuir para a melhoria da qualidade dos impressos brasileiros.

\footnotetext{
${ }^{8}$ Mario da Silva Brito, “São Paulo Literário e Artístico”, Rio de Janeiro, Correio da Manhã, 2ª seção, 2 dez. 1945.
} 
Nas palavras de um crítico da época,

Quando verificamos a pobreza de nossas revistas, inclusive as de luxo, a precariedade de nossas edições, [...] temos que nos lamentar da escassez de elementos. [...] Essa situação não resulta da qualidade das máquinas apenas; sua causa dominante é a falta de elementos humanos com a sensibilidade voltada para esses ofícios, tão merecedores da nossa simpatia e apreço ${ }^{9}$.

Os egressos do curso deveriam, portanto, diminuir essa escassez, uma vez que teriam perfil profissional diverso do dos alunos das escolas técnicas industriais: eles não seriam "operários gráficos", mas sim "artistas gráficos", e atuariam desenhando e projetando impressos, como livros, jornais e revistas, além de ilustrações, anúncios e cartazes publicitários, e não realizando manualmente a composição tipográfica, a impressão ou o acabamento das publicações.

\section{Estrutura e Programa}

As inscrições para o curso foram abertas em abril de 1946 e, para ingressar, os alunos deveriam demonstrar conhecimentos de desenho básico, os quais seriam auferidos por meio da realização de provas de "desenho de objeto iluminado a 450", "desenho da figura humana, com modelo", e "composição imaginativa sobre um tema dado" ${ }^{10}$. Edital de inscrição publicado no jornal Correio da Manhã de 3 de abril de 1946 menciona a exigência de diploma do curso "secundário ou equivalente" para que os alunos pudessem ingressar no curso, porém, de acordo com o folheto de divulgação, seria exigida "prova de conclusão do Curso Básico".

As aulas tiveram início no mês seguinte, em tempo integral, com seis horas diárias de atividades, e o curso estender-se-ia por seis meses.

O programa do curso era dividido em três "disciplinas": Desenho Aplicado às Artes Gráficas, Elementos de História da Arte e das Artes Gráficas e Técnica de Publicidade, sendo que a primeira era subdividida em composição decorativa, xilogravura, água-forte e litografia ${ }^{11}$. As aulas das diferentes técnicas de gravura foram planejadas como a parte experimental do curso, a qual deveria ocupar metade de sua carga horária, de acordo com o programa.

A disciplina Desenho Aplicado às Artes Gráficas, da qual faziam parte as aulas de composição decorativa e de gravura, ocupava, possivelmente, a maior parte do tempo dos estudantes. Seu programa, bastante amplo, seria iniciado, de acordo com o folheto de divulgação do curso, por tópicos dedicados ao desenho em si, tais como luz, sombra, formas, planos, perspectivas e figura humana, passando posteriormente para tópicos mais relacionados às artes gráficas:

\footnotetext{
${ }^{9}$ Celso Kelly, "Letras e Artes: Uma Legítima Escola de Arte”, A Noite, 20 fev. 1947.

${ }^{10}$ Fundação Getúlio Vargas, Divisão de Ensino, Curso de Desenho de Propaganda e de Artes Gráficas [folheto de divulgação do curso], 1946, p. 6.

${ }^{11}$ Esta é a divisão do curso de acordo com o folheto de divulgação distribuído pela FGV, o qual está sendo considerado aqui como principal fonte de informação para a descrição do programa do curso. No edital publicado no Correio da Manhã, de forma diversa, cada uma das aulas de gravura é considerada uma disciplina.
} 
- O desenho e as artes gráficas. Pena, lápis e pincel. Tessitura do desenho. Modos de impressão. Artístico (direto) e mecânico. Xilogravura. Gravura em metal. Litografia.

- A ilustração. O livro. A revista. O jornal. Suas características. A caricatura.

- A ilustração. Prosa e Poesia. Conceito da literatura. Meios de ilustrar.

- O complemento tipográfico. Os alfabetos. A paginação. A escolha de caracteres. $\mathrm{O}$ "clichê".

- O desenho publicitário. Conceito de publicidade. Meios e fins.

- Composição do layout. Da utilização da fotografia. Folhetos, "depliés", menus, marcas, catálogos.

$-0 \operatorname{cartaz}^{12}$.

O programa da disciplina Elementos de História da Arte e das Artes Gráficas previa apresentar aos alunos um amplo panorama da história da arte, da pré-história ao século XX, incluindo, no entanto, como únicos tópicos relacionados às artes gráficas, "a gravura em madeira" e o "desenvolvimento da imprensa".

A disciplina Técnica de Publicidade, sob responsabilidade direta de Santa Rosa, incluía em seu programa aspectos conceituais e práticos da publicidade. Começando pelo "conceito de publicidade", passava por tópicos como "expressão da ideia graficamente", "o desenho publicitário", "humor na publicidade", "harmonia tipográfica com o espírito do anúncio", "importância da ideia em publicidade" e "redação de textos". Constavam ainda entre seus ensinamentos os "meios de reprodução gráfica", incluindo "impressão em relevo, plana e gravada", além de "processos recentes de impressão"13. exercícios:

Por fim, constam ainda do programa do curso, em sua parte prática, os seguintes

\footnotetext{
- Compor layouts para publicidade de modas, medicamento e indústria.

- Realizar anúncios para revista e jornal.

- Desenhar a pena um anúncio para jornal.

- Compor com caricatura um anúncio a que esta se adapte.

- Fazer um cartaz com três cores ${ }^{14}$.
}

Como se vê, o conteúdo programado para os seis meses de curso era extenso, contemplando aspectos históricos, conceituais, técnicos e práticos das artes gráficas. $\mathrm{O}$ profissional que se pretendia formar no curso, portanto, deveria ter uma visão abrangente da matéria, unindo qualidades intelectuais e habilidades manuais.

\footnotetext{
${ }^{12}$ Fundação Getúlio Vargas, Divisão de Ensino, Curso de Desenho de Propaganda e de Artes Gráficas [folheto de divulgação do curso], 1946, pp. 7-8.

13 Idem, p. 9.

${ }^{14}$ Idem, ibidem.
} 
O desenvolvimento do curso, no entanto, não ocorreu exatamente de acordo com o planejado. Em dois relatórios feitos por Santa Rosa preservados nos arquivos da FGV, o orientador do curso relata uma série de problemas enfrentados por professores e alunos. As aulas de litografia, por exemplo, não chegaram a ser ministradas, por falta de oficina. Santa Rosa também solicita, sem sucesso, a instalação de uma pequena oficina tipográfica, que, argumenta, forneceria instrução complementar aos alunos ${ }^{15}$.

Em relação à duração do curso, Santa Rosa solicita à Fundação uma prorrogação de dois meses além dos seis inicialmente programados, em decorrência da impossibilidade de dar ao curso "a orientação que desejava impor, em vista do nível artístico dos alunos". Em virtude do desnível da formação inicial dos estudantes, que teriam ingressado sem preparação suficiente, Santa Rosa relata a necessidade de ensinamentos adicionais antes que pudessem seguir o programa da disciplina de publicidade, justificando assim a conveniência da prorrogação das aulas. Não há documentos evidenciando se a prorrogação foi ou não concedida, mas há diversas referências à duração do curso como tendo sido de sete meses, de maio a novembro - um mês além do previsto, portanto.

Tendo em vista o aperfeiçoamento do curso, nos relatórios Santa Rosa faz ainda sugestões de alterações em relação ao programa inicial, como a inclusão de noções de fotografia entre os tópicos das aulas de publicidade, e a realização de conferências com intelectuais e publicitários, para "criar ambiente favorável aos nossos futuros artistas de propaganda entre os dirigentes das agências do Rio" ${ }^{16}$.

\section{Professores e Alunos}

A orientação do curso, como visto, coube a Tomás Santa Rosa, à época já reconhecido artista plástico, cenógrafo e, de especial interesse aqui, artista gráfico. Com destacada atuação como capista e ilustrador desde o início dos anos de 1930, Santa Rosa era um dos principais capistas da Livraria José Olympio Editora, "casa" dos mais importantes autores da literatura brasileira do período e amplamente reconhecida pela qualidade gráfica de suas publicações. Santa Rosa, além de orientador responsável pelo curso, foi também professor da disciplina Técnica de Publicidade e da parte de composição decorativa da disciplina de Desenho Aplicado.

As aulas de história da arte ficaram sob a responsabilidade de Hannah Levy, alemã refugiada da guerra, com formação na Alemanha e na França e pesquisadora interessada pela arte brasileira do período colonial, que permaneceu no Brasil entre 1937 e $1947^{17}$. As diferentes técnicas de gravura tiveram como professores Axel de Leskoschek, responsável pelas aulas de xilogravura, Carlos Oswald, que ensinava água-forte, e, se tivesse sido implantado o curso de litografia, Silvio Signorelli. Deste último, pouco se sabe, entretanto, os dois primeiros são nomes de importância na história da gravura brasileira, com atuação relevante como artistas e como professores.

\footnotetext{
${ }^{15}$ Tomás Santa Rosa, Curso de Desenho de Propaganda e de Artes Gráficas. Relatório dos Meses de Junho e Julho de 1946, 1946; e Curso de Desenho e de Artes Gráficas, [1946].

16 Idem

${ }^{17}$ Maria Luisa Luz Tavora, “Experiência Moderna: Gravura no Curso de Desenho de Propaganda e de Artes Gráficas Fundação Getúlio Vargas 1946”, 2012.
} 
Carlos Oswald foi um dos precursores da gravura artística no país. Nascido e formado na Itália, filho do compositor brasileiro Henrique Oswald, radicou-se no Rio de Janeiro em 1913 e, já no ano seguinte, foi nomeado professor do curso de gravura do Liceu de Artes e Ofícios, que dispunha de uma oficina para água-forte. Este curso pioneiro, dedicado à gravura artística, teve, no entanto, um pequeno grupo de frequentadores, e só foi retomado em 1930, aí então com sucesso $^{18}$, tendo cumprido a função de despertar o interesse de muitos artistas pela técnica da água-forte.

Axel de Leskoschek, o professor de xilogravura, era outro imigrante refugiado da guerra. Natural de Graz, na Áustria, onde estudou artes plásticas e gráficas, chegou ao Rio de Janeiro em 1941, permanecendo na cidade até 1948. Leskoschek já dispunha de experiência prévia como artista gráfico e ilustrador e em sua estadia no país ilustrou diversos livros, sobretudo para a José Olympio, editora para a qual produziu cerca de duzentas xilogravuras para as obras completas de Dostoiévski, ilustrando, entre outros, os títulos Os Irmãos Karamázov, Os Demônios e 0 Eterno Marido. Para a mesma editora, chegou a projetar capas, como, por exemplo, a da coleção "Memórias, Diários, Confissões", iniciada em 1944. Nesse período, também ajudou a difundir a gravura artística no país, atuando como professor não apenas do curso de artes gráficas da FGV como também em seu próprio ateliê, onde formou uma geração de gravadores.

O perfil daquele que seria o terceiro professor de gravura é bastante diverso. Do que se pode apurar, Silvio Signorelli era servidor da Imprensa Nacional, onde exercia a função de técnico de impressão e litografia offset. Em 1942, foi distinguido pelo governo e realizou estágio de estudos e aperfeiçoamento nos Estados Unidos, trabalhando por cerca de seis meses em estabelecimentos gráficos norte-americanos, junto com outros profissionais da Imprensa Nacional ${ }^{19}$. Do que foi possível verificar, não teve uma carreira artística.

Nos arquivos da FGV, não foi possível obter uma lista oficial dos estudantes que frequentaram o curso, que teriam sido cerca de quarenta. Também não há informações suficientes para se tentar traçar um perfil desses alunos, cujo futuro profissional, em sua maioria, se desconhece ${ }^{20}$. Em entrevista concedida em 1949 a respeito do curso, Santa Rosa elogia o desempenho e a dedicação dos alunos e afirma que parte deles estava então se aperfeiçoando no exterior e que outros "conseguiram boa colocação em casas editoras, trabalham para revistas" ${ }^{21}$, sem entrar em detalhes das atividades desempenhadas por eles. Na mesma entrevista, Santa Rosa menciona que um dos motivos alegados pela FGV para a não continuidade do curso teria sido a existência de "muitos grã-finos" entre seus frequentadores.

\footnotetext{
${ }^{18}$ Leon Kossovitch \& Mayra Laudanna, Gravura Brasileira: Arte Brasileira do Século XX, 2000, p. 38.

19 "Notas Sociais", Jornal do Brasil, [p. 9], 27 ago. 1942; e "O Chefe da Nação e a Imprensa Nacional”, Diário da Noite, p. 1, 15 abr. 1943.

${ }^{20}$ Frederico Morais, que não cita suas fontes, apresenta uma lista de 35 alunos que, entre outros, teriam passado pelo curso: "Teresa Nicolao, Danúbio Gonçalves, Bartolomeu de Andrade, Geo Staempfli, Cláudio Correia e Castro, Mário Simas, Vera Coelho Gomes, Fayga Ostrower, Isabela Sá Pereira, Misabel Pedrosa, Anísio Medeiros, Lucília Carvalho, Eva Turcsany, Lina Hazan, Rita Rosemayer, Aristides Bento de Mecenas, Ramiro Martins, Renina Katz, Paulo Vincent Fonseca, Rachel Sisson, Rachel Strosberg, Francisco Peixoto Filho, Marcelo Souza Leite, Sheila, Zezé, Yllen Kerr, Fernando Clóvis Pereira, Dália Andrade M. F. Alves, Regina Neves, Telmo de Jesus Pereira, Anísio Dantas, Darwin Silveira Pereira, Eisaburo Nagasawa e Almir Mavignier". Frederico Morais, Cronologia das Artes Plásticas no Rio de Janeiro 1816-1994, 1995, p. 196.

${ }^{21}$ Yvonne Jean, “Experiências de Arte Decorativa no Rio”, Correio da Manhã, 11 dez. 1949.
} 


\section{Artes Gráficas, Gravura, Arte Aplicada}

O uso do termo "artes gráficas", parte do nome do curso da FGV, era bastante difundido nos anos de 1940 no Brasil. Em linguagem corrente, podia designar, dependendo do contexto, ao menos três atividades distintas: a) o conjunto das diversas técnicas e etapas necessárias à produção industrial de impressos, tais como livros, jornais, revistas, rótulos, cartazes e outros efêmeros; b) as atividades mais relacionadas ao desenho de peças gráficas, tais como capas, cartazes e anúncios, também chamadas de artes aplicadas e mais tarde abarcadas pelos profissionais das áreas que passaram a ser conhecidas como "design gráfico" e "publicidade"; e c) as diversas técnicas da gravura - xilogravura, linoleogravura, litografia e gravura em metal -, arte ainda pouco considerada no Brasil dos anos de 1940, pois vista como ligada à tipografia, mas cuja apropriação pelos artistas plásticos se iniciava.

Não é de se estranhar, portanto, que um curso de artes gráficas tentasse abarcar todos esses aspectos, com maior ou menor profundidade, buscando formar profissionais aptos a desempenhar uma miríade de atividades, com imbricações e sobreposições. No período em questão, ademais, os campos das artes gráficas e das artes plásticas, da gravura, da ilustração e de outros ofícios ora se afastavam, ora se aproximavam, confundindo-se, muitas vezes, em suas inter-relações.

A ênfase dada pelo curso ao ensino da gravura como arte aplicada talvez se explique, de qualquer modo, em virtude dos interesses de seu orientador, atuante no mercado editorial, que passava por uma fase de efervescência na publicação de livros ilustrados e de edições de luxo. Nessa época, as técnicas de impressão utilizadas nas gráficas, cada vez mais mecanizadas, em grande parte ainda dependiam das técnicas da gravura e, assim, o conhecimento dos artistas gráficos era fundamental para a impressão de livros, em especial os ilustrados.

Para as edições de luxo, produzidas em pequenas tiragens e com gravuras originais, a obra dos gravadores tornava-se especialmente interessante, de modo que o fenômeno atraiu para o livro um contingente de artistas, que nele perceberam uma possibilidade de atuação e de difusão de suas obras. Considerando a demanda desse mercado por ilustrações, no entanto, é pouco provável que os artistas gráficos formados no curso da FGV disputassem, ao menos de imediato, o lugar dos artistas que já atendiam a essa demanda, uma vez que o renome do ilustrador, nesse caso, era essencial para promover e tornar atrativas as edições.

\section{Desdobramentos}

Após a conclusão das aulas, em fevereiro de 1947, promoveu-se uma exposição de obras de parte dos frequentadores do curso, na sede da própria FGV, com boa repercussão na imprensa carioca. Os críticos destacaram, sobretudo, a diversidade das técnicas e dos estilos exibida pelos estudantes e o rápido progresso por eles demonstrado no curto período de duração do curso. Elogiaram também, vivamente, a atuação dos professores, e a liberdade concedida por esses aos alunos, sem impor a eles um caminho único. 


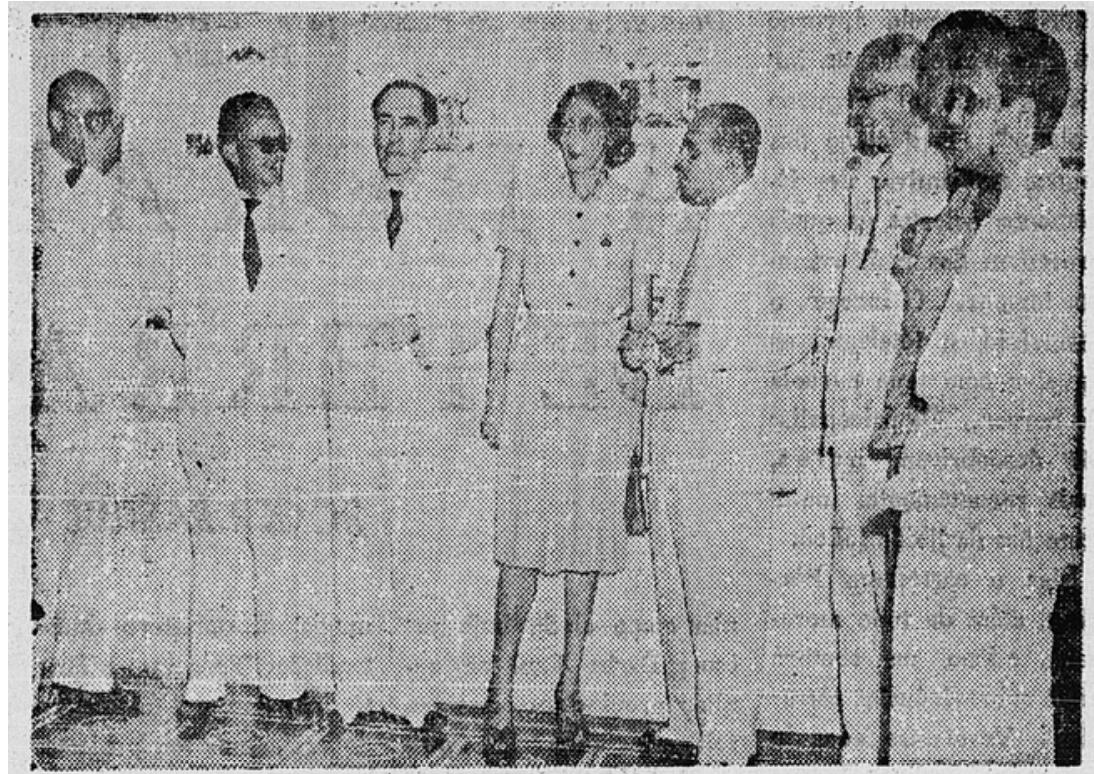

"EXPOSICAO DE DESENHO E DE ARTES GRAFICAS" - Tem alcangado o mais vivo interesse a exposiçāo dos trabalhos dos alunos do "Curso de Desenho e de Artes Gráficas', da Fundagão Getulio Vargas e cuja inauguraçāo se fez quarta-feira última com a presenga de figuras mais representativas do nosso mundo cultural, artistico e social tesse Curso, cujos excelentes resultados sé traduzem nessa primeira exposição é dirigido, superiormente, pele professor Tomas Santa Rasa Jr., com a colaboraçâo dos professores Carlos Oswaid, Hannah Levy e Axel de Leskoschek. A exposiğão permanecerá aberta, d̀ Praia de Botafogo, 186, das 14 as 22 horas, até $o$ dia 20 do corrente. No flagrante acima, tomado no ato da inanguraçüo, vernos os srs. Lucio Rangel, diretor de "Sombra", Consul Roberto Assunsäo, pintor Raul Pedrosa, Prof. Santa Rosa, professara Hannah Levy, prof. Otto Maria Carpeaux, dr. Simeão Leal, diretor do Serviģo de Documentagão do Ministério da Educạão

FIGURA 3. Fotografia da inauguração da exposição dos alunos do curso da FGV, na qual se veem os professores Hanna Levy e Santa Rosa. Publicada em

"Letras e Artes" em 2 de fevereiro de 1947.

O curso, no entanto, apesar de toda a repercussão positiva e do apoio da imprensa, e a despeito dos protestos dos alunos e dos esforços de Santa Rosa, foi descontinuado pela FGV, encerrando-se após a conclusão da primeira turma. Na iminência do fechamento do curso, a exposição dos trabalhos dos jovens artistas foi transferida da sede da FGV para a galeria da Associação Brasileira de Imprensa, como medida de apoio à iniciativa, e lá permaneceu aberta ao público por mais algum tempo, ainda merecendo atenção dos jornais, mas sem êxito no propósito de tentar manter o curso funcionando. O fechamento foi duramente criticado pela imprensa e Mario Pedrosa, por exemplo, escreveu que a suspensão constituía um ato de "selvageria"22.

A decisão da FGV de descontinuar o curso de artes gráficas teria sido motivada pelo seu caráter artístico, em desacordo com a finalidade da Fundação, que seria a de promover o "ensino administrativo e das ciências sociais". Oscar Mello Flores, diretor executivo da FGV, justifica o fechamento afirmando que o curso "não era bastante popular", que o horário diurno impossibilitava a frequência de alunos que trabalhavam e que, "de qualquer maneira, a porcentagem de alunos que se destacaram não fora suficiente" ${ }^{23}$. A impressão da FGV sobre a utilidade do curso e sobre o aproveitamento dos alunos diferia, portanto, da visão de Santa Rosa e da opinião dos apoiadores da iniciativa que se manifestaram por meio da imprensa.

\footnotetext{
${ }^{22}$ Mário Pedrosa, “Artes Plásticas: Selvageria a la Goering”, Correio da Manhã, 21 fev. 1947.

${ }^{23}$ Yvonne Jean, "Experiências de Arte Decorativa no Rio", op. cit.
} 
Superadas as polêmicas da época, cabe questionar o real legado do curso. Se logo após sua realização, como mencionado por Santa Rosa no depoimento anteriormente citado, alguns de seus estudantes já estavam empregados em editoras e na imprensa, não foi possível recuperar informações precisas sobre essa atuação. Devido, sobretudo, ao anonimato de grande parte das tarefas desempenhadas pelos artistas gráficos, mostra-se inviável, no momento, confirmar se a vida profissional dos frequentadores do curso cumpriu efetivamente as expectativas de seus idealizadores.

Entre seus egressos, dos nomes que se conhece, alguns podem ser mencionados como exemplos de destaque nas artes, como Almir Mavignier, Danúbio Gonçalves, Décio Vieira, Fayga Ostrower, Misabel Pedrosa e Renina Katz. Chama atenção, sobretudo, o grupo formado por Danúbio Gonçalves, Fayga Ostrower e Renina Katz, nomes essenciais à consolidação da gravura artística no Brasil, cuja atuação como gravadores continuou nos decênios seguintes, com a produção de obras e a realização de exposições e cursos.

O gaúcho Danúbio Gonçalves, após o término do curso na FGV, prosseguiu seus estudos em Paris e, em seu retorno ao Rio de Grande do Sul, no início dos anos de 1950, participou da fundação do Clube de Gravura de Bagé e, posteriormente, do de Porto Alegre, iniciativas que propunham a popularização das artes gráficas - aqui entendidas como a gravura, considerada arte mais acessível ao público em geral. Gonçalves também foi professor de gravura em Porto Alegre, até fins dos anos de 1970.

Renina Katz, após o término do curso da FGV, também deu continuidade aos estudos, frequentado aulas de gravura em metal no Liceu de Artes e Ofícios do Rio de Janeiro e ingressando na Escola Nacional de Belas-Artes já em 1947. Nesse período, colaborou esporadicamente com ilustrações para a imprensa. Nos anos de 1950, mudou-se para São Paulo, onde atuou como professora no Museu de Arte de São Paulo (Masp) e na Fundação Armando Álvares Penteado (Faap), até ingressar como docente na Faculdade de Arquitetura e Urbanismo da Universidade de São Paulo (FAU-USP) em 1956, instituição na qual permaneceu por três décadas ensinando desenho e gravura e na qual também foi responsável por uma disciplina de comunicação visual nos anos de 1960.

Igualmente importante para a gravura artística brasileira, Fayga Ostrower teve também atuação como ilustradora, área pela qual se interessara mesmo antes do ingresso no curso da FGV. Desde princípios de 1946, Ostrower já colaborava como ilustradora do suplemento "Letras e Artes", do jornal Correio da Manhã, no qual continuou atuando até o início da década seguinte. Nessa segunda metade dos anos de 1940, a artista produz ilustrações para revistas literárias, como Joaquim e Nordeste, expõe gravuras em mostras individuais e coletivas e também nesse período são publicados os primeiros livros ilustrados por ela. Entre 1948 e 1965, Ostrower trabalha ainda com estamparia, criando mais de quinhentos desenhos, escolhendo os tecidos e supervisionando sua impressão ${ }^{24}$.

Entre os possíveis alunos listados por Frederico Morais ${ }^{25}$, há outros nomes que se encontram relacionados a atividades artísticas, à indústria editorial e à imprensa, como Yllen Kerr, que no decênio de 1950 expõe como gravador e desenhista, ilustra livros e chega a dar aulas de

\footnotetext{
24. Informação constante do site do Instituto Fayga Ostrower, disponível em: http://faygaostrower.org.br. Acesso em 25 jul. 2016.

${ }^{25}$ Frederico Morais, op. cit.
} 
gravura no MAM de São Paulo, mas dedica-se profissionalmente sobretudo ao jornalismo, trabalhando como fotógrafo e repórter do Jornal do Brasil, além da pintora Teresa Nicolao, que no decênio de 1960 desenhou algumas capas para a José Olympio.

No campo das artes gráficas mais tarde identificado com os profissionais do design gráfico, vale ressaltar o nome de Almir Mavignier, que prosseguiu os estudos na área frequentando a Escola de Ulm, na Alemanha, país onde se radicou e onde teve uma sólida carreira como professor e cartazista, paralelamente à sua atuação como pintor.

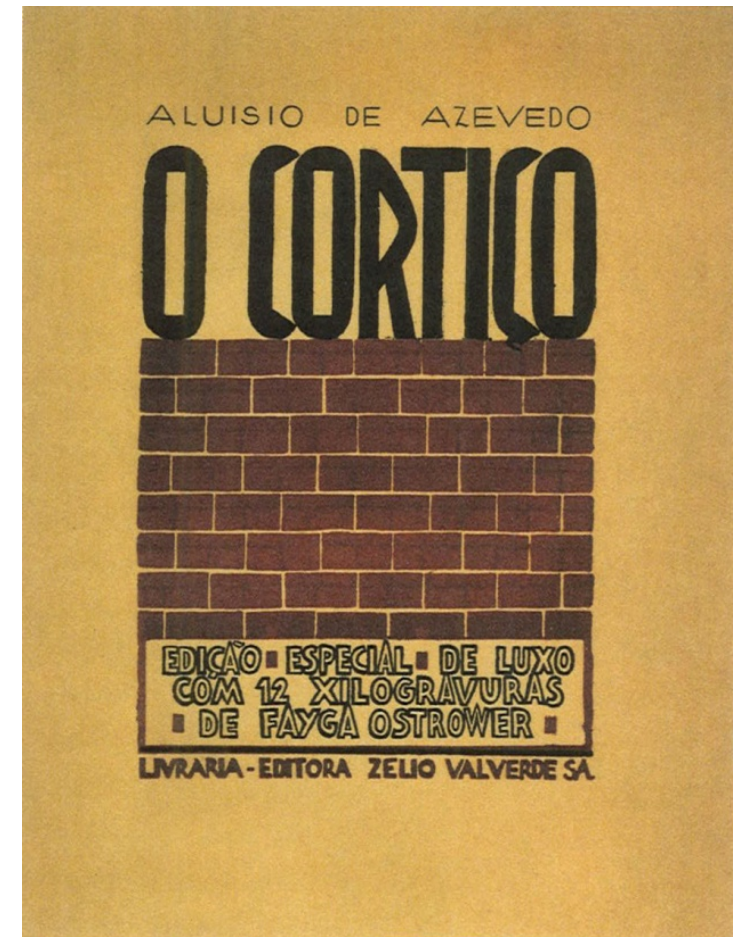

FIGURA 4. Capa de Fayga Ostrower para edição de $\mathbf{O}$ Cortiço publicada com 12 xilogravuras da artista. Rio de Janeiro, Livraria Zélio Valverde, $1948,20,5 \times 27 \mathrm{~cm}, 352$ páginas.

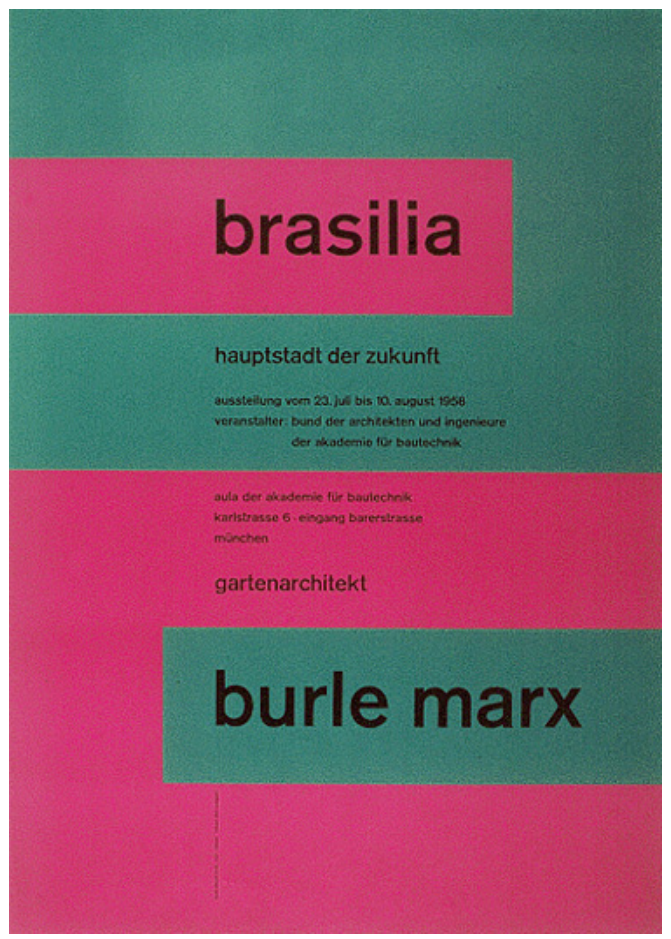

FIGURA 5. Brasilia Burle Marx, cartaz de autoria de Almir Mavignier. Alemanha, 1958, $59 \times$ $84,2 \mathrm{~cm}$, impressão offset.

\section{Conclusão}

O Curso de Desenho de Propaganda e de Artes Gráficas da FGV foi marcado, desde o início, pela aparente contradição entre o objetivo da Fundação de formar profissionais com perfil técnico e o ensino mais "artístico" oferecido pelos professores aos alunos. Como visto, no entanto, artes gráficas, no período, era termo que possibilitava mais de um entendimento, e o curso busca conciliá-los oferecendo desde noções básicas de desenho e de história da arte a técnicas de gravura e de reprodução gráfica.

A iniciativa de tentar formar profissionais das artes gráficas fora do ambiente do trabalho foi pioneira e, talvez por isso, vacilante. Assim, a instituição e o corpo docente divergem no que se refere ao valor e ao proveito do curso: enquanto o representante da FGV, como mencionado, considera que um número insuficiente de alunos havia se destacado, Santa Rosa, como também assinalado, elogia o desempenho dos frequentadores e avalia positivamente a aceitação que 
tiveram pelo mercado. Leskoschek se diz satisfeito porque "os alunos trabalham bastante e estão ávidos por ouvir" e Carlos Oswald, por sua vez, considera que a "concorridíssima" exposição de encerramento "patenteou as classes intelectuais a utilidade e eficiência daqueles cursos" 26 .

Ainda que se ignore a atuação profissional da maioria dos frequentadores do curso, a trajetória conhecida de parte de seus alunos, exemplificada nos parágrafos precedentes, possibilita pensar que a experiência prestou-se à iniciação dos estudantes no campo das artes, permitindo que, após essa formação básica, eles se especializassem em diferentes áreas de atuação relacionadas às artes, plásticas e/ou gráficas, contribuindo efetivamente para seu desenvolvimento.

\section{Referências}

\subsection{Fontes $^{27}$}

\subsubsection{Documentos}

FUNDAÇÃO GETÚlIO VARGAS. Relatório Anual de Prestação de Contas [Relativo a 1945]. 1946. Datiloscrito.

Divisão de Ensino. Curso de Desenho de Propaganda e de Artes Gráficas [folheto de divulgação do curso], 1946.

. Relatório e Balanço do Exercício de 1946. 1947. Datiloscrito.

SANTA ROSA, Tomás. Curso de Desenho de Propaganda e de Artes Gráficas. Relatório dos Meses de Junho e Julho de 1946. 1946. Datiloscrito

Curso de Desenho e de Artes Gráficas. [1946]. Datiloscrito.

Carta ao Diretor Executivo da Fundação Getúlio Vargas. Rio de Janeiro, 4 mar. 1947. Manuscrito.

\subsubsection{Artigos de Periódicos}

"Notas Sociais". Rio de Janeiro, Jornal do Brasil, [p. 9], 27 ago. 1942.

"O Chefe da Nação e a Imprensa Nacional”. Rio de Janeiro, Diário da Noite, p. 1, 15 abr. 1943.

BRITo, Mario da Silva. "São Paulo Literário e Artístico". Rio de Janeiro, Correio da Manhã, 2a seção, 2 dez. 1945.

"Fala o Pintor Santa Rosa sobre o Curso de Artes Gráficas". Rio de Janeiro, A Manhã, p. 3, 24 mar. 1946.

\footnotetext{
${ }^{26}$ Leskoschek manifesta-se em carta de junho de 1946 transcrita por Frederico Morais, op. cit., p. 197, e a avaliação de Carlos Oswald está em documento do decênio de 1950 citado por Helenira Paulino, Carlos Oswald: A Gravura como Obra de Arte na Primeira Metade do Século XX no Rio de Janeiro, 2017, p. 76.

${ }^{27}$. Listadas em ordem cronológica.
} 
"Curso de Desenho: Edital de Inscrição ao Curso de Desenho de Propaganda e de Artes Gráficas". Rio de Janeiro, Correio da Manhã, 3 abr. 1946.

"Noticiário". Rio de Janeiro, Correio da Manhã, 1ㅇ fev. 1947.

"Exposição de Desenho e de Artes Gráficas". Rio de Janeiro, Suplemento Letras e Artes, A Manhã, p. 2, 2 fev. 1946.

Bento, Antonio. "O Curso da Fundação Getúlio Vargas". Rio de Janeiro, Diário Carioca, 13 fev. 1947.

Pedrosa, Mário. "Artes Plásticas: Curso de Desenho e Artes Gráficas". Rio de Janeiro, Correio da Manhã, 15 fev. 1947.

Kelly, Celso. "Letras e Artes: Uma Legítima Escola de Arte". Rio de Janeiro, A Noite, 20 fev. 1947.

Pedrosa, Mário. "Artes Plásticas: Selvageria a la Goering". Rio de Janeiro, Correio da Manhã, 21 fev. 1947.

"Deve Intervir na Fundação Getúlio Vargas o Ministro da Educação. Impõe-se a Reabertura do Curso de Artes Gráficas - Os Dirigentes não se Interessam". Rio de Janeiro, Diário Carioca, 28 fev. 1947.

Bento, Antonio. "Alunos da FGV na ABI". Rio de Janeiro, Diário Carioca, 11 mar. 1947.

Kelly, Celso. "Letras e Artes: Um Curso, Um Programa, Uma Realidade”. Rio de Janeiro, A Noite, 12 mar. 1947.

JeAN, Yvonne. "Experiências de Arte Decorativa no Rio". Rio de Janeiro, Correio da Manhã, 11 dez. 1949.

\subsection{Bibliografia}

Almir da Silva Mavignier. Disponível em <http://www.mavignier.com>. Acesso em 25 jul. 2016.

AxI Leskoschek e seus Alunos. Brasil/1940-1948. Galeria de Arte Banerj, Ciclo de Exposições sobre Arte no Rio de Janeiro, 1985. [Catálogo de exposição com curadoria de Frederico Morais]

Bueno, Luís. Capas de Santa Rosa. Cotia: Ateliê Editorial, 2016.

BRunelli, Silvana. Diálogo entre as Artes Plásticas e a Publicidade no Brasil. Tese de Doutoramento em Artes Plásticas. Escola de Comunicações e Artes da Universidade de São Paulo, 2007.

FERRAZ, Eucanaã (org.). Fayga Ostrower Ilustradora. Rio de Janeiro: Instituto Moreira Salles, 2011.

Kossovitch, Leon \& LaUdANnA, Mayra. Gravura Brasileira: Arte Brasileira do Século XX. São Paulo: Itaú Cultural, Cosac Naify, 2000.

Instituto Fayga Ostrower. Disponível em: <http://faygaostrower.org.br>. Acesso em 25 jul. 2016.

MoRAIS, Frederico. Cronologia das Artes Plásticas no Rio de Janeiro 1816-1994. Rio de Janeiro: Topbooks, 1995. 
Paulino, Helenira. Carlos Oswald: A Gravura como Obra de Arte na Primeira Metade do Século XX no Rio de Janeiro. Dissertação de Mestrado em Estudos Brasileiros. Instituto de Estudos Brasileiros da Universidade de São Paulo, 2017.

SANTA Rosa, Tomás. Roteiros de Arte. Rio de Janeiro: Serviço de Documentação, Ministério da Educação e Saúde, 1952.

TAVORA, Maria Luisa Luz. Experiência Moderna: Gravura no Curso de Desenho de Propaganda e de Artes Gráficas - Fundação Getúlio Vargas 1946. In: 21ํㅡㄹ Encontro da Associação Nacional dos Pesquisadores em Artes Plásticas. Rio de Janeiro: 2012. 